\title{
Students' Problems with Cohesion and Coherence in EFL Essay Writing in Egypt: Different Perspectives
}

\author{
Abdel Hamid Ahmed \\ Helwan Faculty of Education, Egypt
}

\begin{abstract}
The current study focuses on the organisational problems that Egyptian student teachers of English encounter when they write an English essay. In particular, the current study aims at investigating students' cohesion and coherence problems in EFL essay writing. A mixed method research design was used including a questionnaire and a semi-structured in-depth interview. Analysis of findings revealed that students encounter some problems in the cohesion and coherence of EFL essay writing. Discussion and implications of these findings are presented.
\end{abstract}

\section{Introduction}

Students' writing in an EFL classroom context should show their awareness of their own communicative goals, of the reader, and of the writing context. Essay writing, which constitutes a problem for many ESL/EFL students worldwide, is a major challenge for many student teachers of English at Helwan Faculty of Education in Egypt. Despite numerous approaches to the teaching of writing having evolved from different teaching methods, tackling EFL writing is still one of the most challenging areas for teachers and students. Egyptian student teachers of English at Helwan Faculty of Education have to pass many academic courses in English. Nevertheless, these students still experience some problems in the cohesion and coherence of their English essay writing as indicated by the results of a preliminary essay writing questionnaire administered to one hundred students.

To the best of my knowledge, most of the Egyptian studies conducted in the field of essay writing at the university level are, however, quantitative. The problem of the current study is concerned with exploring the organisational problems that Egyptian student teachers of English encounter while composing their essays in English.

EFL lecturers and students face certain problems in teaching and learning writing. As many teachers of English have noted, acquiring the writing skill seems to be more laborious and demanding than acquiring the other language skills [63]. In fact, producing a coherent piece of writing is an enormous challenge, especially in one's second language [48]. This is magnified by the fact that the rhetorical conventions of English texts- the structure, style, and organization-often differ from those in other languages [42] as they require a great effort to recognize and manage the differences. This is particularly true of the rhetorical conventions of the Arabic language as students' mother tongue.

In many Arab countries including Egypt, the education systems emphasise writing for taking tests. In this respect, some studies in the Arab world and a few Egyptian studies were conducted offering different approaches and remedial programmes to overcome the decontextualisation of writing and to develop students' EFL essay writing skills [21].

The current study attempted to find answers to the following research questions:

1- How do Egyptian student teachers and their lecturers perceive the cohesion of the written essays?

2- How do Egyptian student teachers and their lecturers perceive the coherence of the written essays?

\section{Literature Review}

The purpose of this literature review is threefold: define EFL/ESL writing, highlight the importance of writing to EFL students, and shed light on some aspects related to EFL Arab students' organisational writing problems with special reference to cohesion and coherence.

\subsection{Definition of Writing}

Writing is defined as "a reflective activity that requires enough time to think about the specific topic and to analyse and classify any background knowledge [11]. Then, writers need a suitable 
language to structure these ideas in the form of a coherent discourse." Lately writing is seen as "a complex activity, a social act which reflects the writer's communicative skills which is difficult to develop and learn, especially in an EFL context” [59]. Recently, views L1 writing is perceived as being composed of three domains: a cognitive psychological perspective, a socio-cultural perspective and a linguistic perspective [47]. In line with the process writing approach adopted in the current study, I perceive EFL writing as a multidimensional process composed of a cognitive activity affected by a number of linguistic and contextual factors; EFL linguistic proficiency, instructional, psychological, socio-cultural, and socio-political issues. If these factors are welladdressed, this will make writing an unforgettable experience.

\subsection{Importance of EFL/ESL Writing}

EFL/ESL Writing has always been considered an important skill in teaching and learning. As commented by Rao, EFL writing is useful in two respects: First, it motivates students' thinking, organizing ideas, developing their ability to summarise, analyse and criticise. Second, it strengthens students' learning, thinking and reflecting on the English language [51].

In relation to the context of the current study, essay writing is significant to the learning of Egyptian student teachers of English because it facilitates student teachers' acquisition of the basic study skills needed for understanding what they study and expressing it in their own words. This will assist them to keep away from memorization, rote learning and plagiarism that are much discouraged in the recent theories of teaching and learning. In addition, competence in essay writing will help students pass all their academic courses successfully. Moreover, being proficient in essay writing in English will enable student teachers of English to be successful teachers and action researchers in the future.

\subsection{Coherence}

Coherence, or texture, is the combination of semantic configurations of two different kinds: register and cohesion [29]. Coherence in written text is "a complex concept, involving a multitude of reader- and text-based features" [Johns, 1986: p.247]. Text-based features mean cohesion (i.e., the linking of sentences) and unity (i.e., sticking to the point). Reader-based features mean that the reader interacts with the text depending on his/her prior knowledge. Coherence is defined as "the organization of discourse with all elements present and fitting together logically” [33]. This denotes that a coherent essay consists of an introduction, a thesis statement, rhetorical support, and a conclusion.

A number of research papers in the Arab world have spotlighted students' coherence problems in English writing. For example, Arab students' written texts revealed that repetition, parallelism, sentence length, lack of variation and misuse of certain cohesive devices are major sources of incoherence and textual deviation [49]. In addition, other studies asserted that Yemini and Moroccan students have some weaknesses, in terms of coherence and cohesion, manifested in the students' written texts.

\subsection{Cohesion}

In relation to EFL essay writing cohesion, many researchers agree that cohesion, on the macro level is related to linking ideas whereas on the micro level, it is concerned with connecting sentences and phrases. "The concept of cohesion is a semantic one; it refers to relations of meaning that exist within the text, and that define it as a text" [29:4]. Many researchers have highlighted the importance of text cohesion claiming that a text stands as a text by means of cohesion. But for cohesion, sentences would be fragmented and would result in a number of unrelated sentences [33].

Reviewed studies pinpointed that cohesion constitutes a serious problem to Arab students. Many researchers in different countries in the Arab world have paid our attention to the different aspects of cohesion problems from which students complain.

However, to the best of my knowledge, no single Egyptian study tackled coherence and cohesion in students' English writing. Hence, the current study is exploring the coherence and cohesion problems that Egyptian student teachers of English face in their English essay writing. This, in turn, will inform my research whether these problems in the Egyptian context are similar to or different from those of the previously reviewed studies.

\section{Analysis of Findings}

In view of the exploratory nature of the current study, and its context-specificity, the naturalistic orientation of interpretive, qualitative research is an appropriate choice. The interpretive approach will help the researcher explore and understand the context within which essay writing in English is taught and learnt at Helwan Faculty of Education in Egypt. This, in turn, will help the researcher reveal the problems that Egyptian student teachers of English encounter in the cohesion and coherence of their written essays.

The sample of the current study consisted of one hundred and sixty five student teachers of English of whom fourteen were selected to be interviewed. In addition, seven essay writing lecturers filled in the questionnaire and were interviewed. The current 
study made use of a questionnaire and a semistructured interview.

Findings of the current study revealed that Egyptian student teachers of English experience some coherence and cohesion problems in their English writing. In relation to coherence problems in their English writing some problems were revealed such as difficulty writing the introduction, the thesis statement, the topic sentence, writing concluding sentences and writing the conclusion. In the same vein, university lecturers reported that their student teachers have difficulty writing the thesis statement, the topic sentences, transition of ideas, and sequence of ideas.

A number of reasons are associated with students' coherence problems in English essay writing. First, the effect of topic-specific background knowledge was seen as influential on the general quality and local coherence of student writing [38]. Second, it was highlighted that low English proficiency students find it difficult to develop coherent writing due to paying attention to language matters rather than making meaning [40]. Moreover, it was indicated that Arab university students tend to follow certain techniques in their written English that make their writing incoherent such as including a broad statement in the opening sections of their essays before introducing the topic sentence [5]. In addition, Arab students overused coordinate sentences and misused topic sentences which were the reasons for their incoherent and unacceptable quality of writing [22].

In reference to student teachers' problems in cohesion, some were reported such as difficulty in using cataphoric and anaphoric reference, ellipsis, substitution, and genre related cohesive ties. In addition, overusing certain cohesive ties was also reported by university lecturers. Diverse studies have acknowledged the importance of text cohesion in English writing as a mechanism that facilitates discourse flow. These studies also added that constructing cohesive texts by second language learners requires focused instruction and additional attention [52]. Besides, many reviewed studies asserted that writing cohesively in English constitutes a serious problem to Arab students.

\section{Discussion}

Findings of the current study revealed that there are a number of factors and contexts lying behind these different coherence and cohesion problems. At the psychological level, students faced a number of challenges including lack of motivation, lack of selfconfidence, and writing anxiety.

Egyptian student teachers of English are not motivated to write English essays for a number of possible reasons. First, they are taught in a large class characterised by physical as well as intellectual distance between teachers and students. Second, Egyptian university teachers tend to use traditional teaching techniques such as lecturing, reading aloud, and book reading; they are frequently indifferent to students' communication in class; and students report negative attitudes towards essay writing as a difficult course. These factors are similar to what another study in Egypt revealed such as "signs of boredom", "passive watching" and "teaching spectacle" [34]. Recently, it has been referred to the impact of students' passive listening on their learning in general and creative writing in particular [2]. Finally, this lack of motivation can have a strong negative effect on students' development in essay writing as confirmed by a researcher who claims that Arabic speaking students are known to face such problems in compulsory English composition courses at the university level [7]. Furthermore, another study has corroborated that students' low motivational intensity contributed to students' vocabulary problems in writing [3].

Students' lack of confidence could be ascribed to a number of socio-cultural issues. First, parents' culture of control and power might be a contributing factor as they indirectly implant a lack of selfconfidence in their children by marginalizing their opinion and voice in the family. Students fear their parents; this is common in the Egyptian context where many parents are ready to punish their children when the need arises. This punishment could be psychological in most cases and physical in some cases. Furthermore, students frequently have a culture of dependence on someone else to tell them what to do. It is widespread among many Egyptians that they depend totally at home on their parents or elder siblings. Independence in study is an uncommon phenomenon in the Egyptian culture. Another important factor is the unrealistic academic/scholastic expectations that families place on their children's shoulders. Parents might expect their child to achieve high expectations beyond his/her intellectual abilities. In reference to the educational system in Egypt, students in classroom are not given the opportunity to argue or negotiate meaning with their teachers. This might be due to the fear of the teacher's strong authority in the classroom. Moreover, Egyptian teachers tend to attract students to their private tuition where they can get all content knowledge summarised and memorised. All these factors might be the original source of lacking self-confidence among most Egyptian students.

Most learning environments at Egyptian governmental universities do not tend to promote students' self-confidence. This is magnified by the fact that highly confident students are not provided with the learning opportunities at university that enhance their confidence and abilities due to the lack of time and teachers' awareness of these 
psychological aspects in promoting students' learning as well as scarcity of teachers' feedback on students' writing performance. It is underscored that writing multiple drafts, putting emphasis on the "publication" of students' work, and teacher's comments that focused more on content and organization than on grammatical errors helped them produce better pieces of written composition and develop more self-confidence in writing [61]. Similarly, it is claimed that when students are selfconfident/competent in their reading and writing skills, they are able to adapt to new teaching/learning methods quickly [4]. Therefore, a psychologically supportive and nurturing learning environment is needed within the Egyptian context to boost students' self-confidence and alleviate their psychological challenges.

Writing anxiety is said to negatively influence both the learners' motivation [13] and their academic achievement [43] on one hand and their attitudes towards writing on the other hand [6]. Research has shown that high apprehensive writers, in comparison with other low apprehensive ones, tend to stop more while composing [31] and are less concerned with planning the overall structure of their essays [57].

In the Egyptian context, data analysis revealed a number of factors that might have contributed to Egyptian students' writing anxiety such as lack of written feedback, negative oral criticism, working under time pressure, and writing about difficult topics. A study within the Egyptian context highlighted that students with low apprehension wrote better quality pieces of written composition and had higher self-esteem than those with high apprehension [30]. In addition, it is pinpointed that students' writing anxiety is caused by their prior negative evaluations or by more complex psychodynamics [54]. In reference to feedback, it was shown that the peer feedback group of prospective teachers experienced significantly less writing anxiety than the teacher feedback group as they received opinions from their classmates to elaborate on, and this collaboration helped them look at their essays differently and lessen their writing anxiety [37]. Moreover, it is implied that writer's block that leads to their anxiety in writing may be due to students' writing under time pressure [41]. Finally, it was reported that students with high apprehension selected topics that were more familiar to them and avoided unfamiliar topics [41].

At the teaching level, a number of factors contributed to Egyptian students' different writing challenges such as teaching workload, limited lecture duration, scarcity of teachers' professional development, teachers' negative attitudes towards teaching essay writing, and the essay writing course.

Teaching workload is one of the factors affecting essay writing teachers' performance and quality of teaching. Academic and general English language courses are taught by English Department teachers or teaching assistants who are employed by the Faculty of Arts. These are few in number compared with other departments and faculties, but they have to teach many academic English courses for all English departments at the Faculty of Arts and the Faculty of Education. Furthermore, they are responsible for teaching general English courses to all the different departments at the twenty faculties at university, often in different places (i.e. Ain Helwan, Helwan, Giza and Zamalek campuses).This results in over workload. An appropriate academic workload is one among other factors that contributes to efficient learning and teaching: when workload increases, learning and teaching might not be as efficient as it should be [50]. In addition, it is implied that heavy teaching loads might hinder students' involvement in different writing activities [2]. Similarly, the issues of workload and pupil behaviour are two of the most important factors that discourage teachers from joining the profession or push them to leave teaching [9].

The lectures on the essay writing course are scheduled to last for two hours a week for each year at the faculty of education. Throughout the classroom observation of the three different lectures, it has been noted that the lecture time is short, ranging from 50-90 minutes, according to the lecturer. Moreover, all teachers combine the two lectures that are supposed to be in different days in only one lecture because they want to find times to teach other courses in other campuses. This reflects the lack of administrative organization and lack of accountability. This issue has also been noted in other international research studies and led to a call for greater accountability and improvement in the quality of teaching in higher education [8].

Staff development refers to providing teachers with opportunities to reflect considerably on their practice and to acquire new knowledge and beliefs about content, pedagogy, and learners [16]. Egyptian lecturers' lack training not only in classroom management techniques, but also in syllabus planning, design, classroom interaction techniques and teaching methods [34]. This is also true of the lecturers in this study, who, as mentioned above, may not have received appropriate training. Professional development could take place through special programmes or through encouraging greater teacher collegiality, which is important for two reasons: it may enhance better working relationships that may yield quality teaching and learning and, it encourages through social interaction a better emotional health environment among staff, which decreases emotional strain and burnout [36].

Egyptian essay writing teachers at HFE are assumed to be developing themselves professionally and academically. However, not all of them do so regularly in their areas of expertise. In reference to 
post-doctoral research, they are supposed to produce five research papers every five years. They rarely conduct studies that are related to their classroom teaching practices because they are graduates of English literature and linguistics, but not applied linguistics. They lack research productivity for a number of reasons including lack of time, teaching support, collegiality, financial and institutional resources, as well as limited salaries, family commitments and daily routines.

Teacher educators' work as researchers is advantageous for three reasons [14]. Firstly, teachers can relate research to practice in a significant way that would positively affect teacher way of thinking and teaching practices, and student achievement outcomes [44]. Secondly, it will enable teacher educators to question policies affecting teacher education. Additionally, it will lead them to find out new problems continuously and enhance their research productivity [35]. In this way, they would be leaders in researching their disciplines and pioneers in promoting more critical and creative students.

There are socio-economic reasons that might impede university teachers from reading the latest periodicals and books in their area of expertise: namely, low monthly salaries, high living expenses, the high cost of books and the expensive periodical subscription. Second, they do not have time to do research as most of them work in other private universities in Egypt to increase their limited salaries. Moreover, using deficient libraries that are full of outdated books in different specializations is another reason for not reading regularly [53]. Furthermore, the post-doctoral research experience that requires them to produce only five research papers in five years, to be promoted to a higher position of assistant professor or professor might contribute to their limited reading. Finally, from a personal experience in buying books for the HFE library, the annual limited budget to buy new books is not enough to buy ten books in English at most, in different specializations.

Teachers' attitude towards teaching is considered a contributing factor to their success and effectiveness in teaching [28]. Egyptian essay writing teachers' attitudes towards their work is mostly negative, with six participants commenting on it as 'difficult', 'hard', and 'challenging'. This attitude might have resulted from some reasons: large classes, the lack of essay writing syllabus, lack of good collegiality, lack of experience and knowledge and the multi-componential nature of essay writing.

In reference to the Egyptian context, there are other factors related to the course that added to the challenges lecturers encounter in their teaching of essay writing. First, there are neither course description, clear course objectives nor course structure to guide students and teachers. This leads to the varied teaching focuses of the different teachers involved in the writing course, as well as the range in materials selected and used, which include essay writing books, extracts of books, internet articles and essays, grammar extracts, idioms and collocations...etc. These factors result in an essay writing course lacking in coherence, structure and guidance.

At the socio-political level, restriction of Egyptian students' voice in writing was underscored. Socio-politically, the Egyptian constitution granted each citizen the right to express his/her opinion freely and clearly. This is well-expressed in article (47) of the Egyptian constitution as follows: "Freedom of opinion is guaranteed. Each individual has the right to express his/her opinion and to publicise it verbally or in writing or by photography or by other means within the limits of the law. Selfcriticism and constructive criticism are the guarantees for the safety of the national structure" [20].

Due to the lack of freedom to express one's opinion, the teaching and learning in higher education have been negatively affected. EFL essay writing is also affected by this opinion suppression. The effect of this lack of freedom of expression is seen in the essay writing course, for example, in the case where a university teacher asked her students to avoid writing their essays about sensitive issues such as religion, politics or sex. There may be a number of reasons including the difficulty of addressing 'taboo' subjects, the concerns of the teacher about doing anything against the regime and which might put her job at risk.

In compliance with the above mentioned example of the essay writing teacher, there are two other student-related examples in writing that took place at the pre-university level in Egypt. The first one tells of a final year technical secondary school male student in Luxor called Safwat Ahmed Mohamed who criticised in writing in the essay section of an Arabic exam the Egyptian regime and defended the Egyptian poor people. As a result, the young man has been deprived from continuing his studies for two years. When asked about this, his friends at school said that he is poor and he could not afford to pay bribes or buy gifts to the exam vigilants to let him cheat in the exams like what most of his rich friends did [27].

The second example narrates the story of a first year secondary school female student in Cairo called Alaa Farag Moujahed who criticised in writing in the essay section of an Arabic exam the Egyptian regime and accused the USA and Israel of polluting the environment. Unlike Safwat, the president intervened asking that Alaa's exam paper to be remarked, resulting in passing the exam successfully and being transferred to second year secondary [58]. The above 
two examples show how dangerous it is to express your opinion frankly in writing. This might result in capturing students' critical and creative thinking skills which are required for better graduates who could lead future generations.

Finally, Egyptian students' essay writing was reported to be affected by a number of socio-cultural contexts such as the reading culture and its effect on essay writing development, students' prior knowledge, pre-university learning experiences such as the use of formulaic expressions, rote learning, lack of discussion and competitive learning environments, Arabic interference in English writing, and proficiency level in English.

Findings of the current study highlighted that university teachers have voiced their concern about their students' lack of reading authentic English texts resulting in considerable challenges with regards to topic prior knowledge, coherence, cohesion, style, range of vocabulary, and grammatical structures and punctuation. Moreover, teachers reported that students frequently read the simplified texts of novels and plays. They are not used to reading for long hours and they are not ready to exert that effort. This is likely to impact on English writing because the more one reads, the better writing style and vocabulary one develops.

To highlight how strong and close the relationship between reading and writing should be, it is capitalised that the teaching of reading and writing are inseparable [62]. Pedagogically, it was suggested that $\mathrm{L} 2$ reading would help improve L2 writing at the beginners and the advanced levels [10]. In line with this, it has been confirmed that reading for pleasure and mandatory reading affect developing composing skills positively [25]. In reference to the Egyptian context, the importance of reading to enhance students' prior knowledge was highlighted [23]. He added that the teaching of reading and writing should be integrated to better prepare English teachers to read like writers and write like readers.

There may be a number of reasons for this lack of extensive reading, including lack of encouragement from parents, lack of financial resources, lack of sufficient and well-equipped libraries, lack of interest in collecting books and keeping them in a home library and associating reading with homework or study.

Prior knowledge plays an important role in one's comprehension and composition [32]. Gaining prior knowledge about general issues enables students to compose an essay about a topic in which they might be interested. Prior knowledge and experience that students bring to the composition classroom are pinpointed as major distinctive characteristics between native and non-native speakers of English [26]. They add that background knowledge and strategic proficiency can be clearly seen in ESL/EFL students' responses to texts and topics, in their reactions to the activities of ESL writing classrooms, and in their familiarity with the rhetorical patterns of academic and professional discourse communities.

Findings of the current study revealed that Egyptian student teachers of English lack topic prior knowledge. This was supported by the views of both students as well as their university teachers. In agreement with this, it was claimed that there is a strong and consistent relationship between topicspecific background knowledge and the quality of students' writing [38]. She further found out that different kinds of knowledge were predictive of success in different writing tasks. In the same vein, prior knowledge and writing experiences seemed to affect students' revision processes more than any other factors [56]. Prior knowledge about written English is thought to be one among other influential factors in students' success [24]. Moreover, it is spotlighted that "when content and form are familiar, reading and writing are relatively easy. But when one or the other (or both) are unfamiliar, efficiency, effectiveness, and success are problematic" [52].

Characteristics of the way EFL writing is taught at the different pre-university stages might be attributed to a number of reasons. First, Egyptian inservice teachers have not been adequately taught how to teach EFL writing well to their students. Therefore, they resort to teaching them formulaic expressions and traditional writing topics. Second, EFL teachers might lack the content knowledge about the different composition writing topics because they do not have time to read in English whether at school, as they are busy teaching, or after school when they start giving many private lessons to increase their limited salaries that hardly suffice their basic needs. Moreover, teachers do not have time to read students' pieces of writing and give them written feedback. Finally, teachers' marking scheme of students' written pieces in the final exams is rather subjective depending on their personal evaluation only.

Rote learning is one of the features characterizing the Egyptian pre-university educational system. Students are encouraged to memorise what they study rather than engage in critical and creative thinking processes. Culturally, Egyptian students who memorise what they study are regarded as cleverer than those who do not. This is reinforced by most exams in the different educational stages in most courses which ask students questions that mostly require them to recall what they have memorised during their study. This leaves no place for the development of critical or creative thinking skills. Schooling is thereby driven exclusively by the need to score high grades in national examinations, which determine access to university places. These exams do not only engender a culture of fear and frustration, but also reinforce rote memorization and 
suppress critical thinking and creative expression [17].

Another reason might be that memorization is a successful learning strategy with some students. This might date back to the time when children were enrolled in what was called at that time 'Kottab', referring to a place where students used to memorise the Holy Qur'an under the instruction of a religious teacher called 'Sheikh'. Furthermore, many Egyptian preparatory and secondary school teachers lack the knowledge and the skills of using differentiated teaching strategies that help them develop students' critical and creative thinking skills.

Additionally, the gap between what Egyptian teachers learn at university and what they practise inside the classroom might help explain why memorization and rote learning are still encouraged. Experienced in-service teachers transfer their experience to the newly-graduated teachers by telling them what works in teaching and what does not work. From a personal experience as an EFL teacher for one year and a supervisor of student teachers of English at different schools for many years, I was told that I should forget all about the teaching techniques that I learnt at university and follow what experienced teachers do in their classrooms by helping students memorise list of words and grammar rules without understanding them. Furthermore, teachers used to train students to memorise steps for answering exam questions correctly. This suggests that learning that is based on memorization and rote learning is soon to be forgotten. This justifies why teachers should pay attention to using a number of different teaching techniques that could help widen their students' minds to think critically and creatively. This might cultivate a better learner who is adaptable to the rapidly-changing education worldwide.

Egyptian student teachers of English "were never in a position to negotiate what the lecturer put on the blackboard.” [34]. This denotes that they are lacking the opportunity to discuss or negotiate meaning in what they learn. This could be attributed to the broader political concept of the so-called 'democracy' where democratic slogans are not put into practice. In other words, the decisions made by the government in relation to certain issues in Egypt are unquestionable. The same thing applies to the small classroom in the Egyptian educational system where 'a democratic class' in which meaning is coconstructed and equal participation is everyone's right, is rare to be found.

The Egyptian educational system, at both the preuniversity and at the university level, is believed to encourage competitive learning environment [1]. In an Egyptian classroom, students are ranked according to achievement that is based on competition. This has resulted in teachers' making some challenging exams that allow only smart students to pass and require other students to resit some exams or repeat the whole scholastic year. Students compete due to some socio-cultural factors such as teachers and parents' encouragement of such kind of learning in classroom and at home. The learning of essay writing in such a competitive learning environment explains the lack of peer review and co-operative learning, as students are afraid of their ideas being stolen and losing their unique thoughts. This is also confirmed by a research study in another EFL context at the university level which reported students' unwillingness to share their writing with their peers in Iran [2].

Egyptian students seem to be the product of an educational system that does not encourage cooperative learning or interaction between learners. Data analysis revealed that students have no access to recent books in the libraries. As a result, they have acquired a number of psychological traits that encourage selfishness, jealousy of other competitors, love of self and monopoly of knowledge. The lack of resources and facilities makes competition more fierce which might justify the lack of co-operation. An example of this can be found in the experience of Prof. Zewail, the Egyptian Nobel Laureate for Chemistry, who narrated on an Egyptian TV programme that he used to hide his laboratory materials and results in a locker when he started his $\mathrm{PhD}$ studies in the USA. Astonishingly, when he arrived the next day, he found out that his laboratory colleague has left him a note saying that these are the latest laboratory results to which he reached. His American colleague did this to ask Prof. Zewail to start where he ended and co-operate as one team. This draws our attention to the bad psychological effects of this kind of competitive learning environment that should be eliminated from our Egyptian educational system by looking ahead at how more developed countries with their ample resources and facilities nurture a supportive environment that encourages knowledge dissemination and stresses collaborative work that leads to ongoing productivity and progress.

It has been acknowledged that producing a coherent, cohesive, well-organised piece of writing is a challenging task. This is magnified by the fact that the rhetorical conventions of English texts such as the structure, organization, lexis and grammardiffer from those in other languages [42] and particularly in Arabic [55]. With special reference to EFL/ESL students in general and Arabic speaking students in particular, learning English essay writing is not easy due to the difference between the two languages in phonological, morphological, transfer, lexicogrammatical and structural aspects that allow problems in students' writing to arise [12]. Thus, these differences need to be recognised and managed. 
In line with the findings of the current study in relation to Arabic interference in students' English writing, a handful of other studies have revealed how Arabic negatively interferes in EFL writing. First, the contrasting features between Arabic and English have been identified as potential contributors to observed error production and weaknesses in some reading skills, but most particularly in writing skills [60]. Second, weakness in mastering one's native language such as Arabic in the current study might account for their weakness in EFL writing skills [18]. Third, the interference of Arabic in the English writing might justify the errors in English grammar and punctuation as confirmed by Mourtaga in his study about Palestinian students [46].

Due to differences between Arabic and English, Egyptian students might find English writing argue that the cultural differences between Arabic and English speech communities are directly responsible for the different use of cohesive devices in the two languages [45]. They claim that Arabic cohesion is characterised as context-based, generalised, repetition-oriented, and additive. In contrast, English cohesion is described as text-based, specified, change-oriented, and non-additive. In my view, I think that Arabic affects the cohesion of Egyptian students' writing. This is represented in Egyptian students' many literal translation and use of formulaic expressions in their writing. In addition, writing the run-on sentences and repetition were another two features of Egyptian students' poor writing style.

Findings of the current study highlighted that Egyptian students' low proficiency in English is an influential factor contributing to their writing problems. This is clear in two aspects: first, university teachers reported that their students join university with a poor proficiency level in English. This foreshadows the numerous problems students are expected to encounter in the various academic courses in general and in EFL essay writing in particular. Second, students themselves voiced their concern about not peer reviewing each others' written essays because they think that they share a low proficiency level which would not enable them to spot each others' mistakes.

In consistency with the findings of the current study, some researchers argued that proficient learners of English are said to produce good quality pieces of writing [15]. For example, a number of factors including student writers' L2 proficiency might influence students' level of knowledge and writing in English [19]. In a similar vein, it has been revealed that L2 higher proficiency participants devoted less time to formulation, concentrated formulation in the central stages of composing in English [39]. In addition, it is proved that secondlanguage proficiency is a significant factor in developing the overall quality of students' written products [15]. However, he added that proficiency did not obviously influence the processes of composing.

\section{Contribution to Knowledge}

The current study contributes significantly to EFL higher education in Egypt in terms of English language pre-service teacher education, educational research, and curriculum planning and design.

From the perspective of English language preservice teacher education, the current study has the potential to improve English language teacher education in a number of ways:

a) It provides an understanding of the problems faced by student teachers in the cohesion and coherence of their written essays. This, in turn, is significant for teacher educators since it aims to provide implications for developing their essay writing syllabus, methods of teaching, and assessment.

b) It also sheds light on the importance of students' needs as this will enable teacher educators to know how to satisfy these needs and conduct successful and memorable learning.

c) It also highlights the significant development in the academic achievement of students in other courses due to their ability to produce coherent and cohesive essays. This will help better prepare highly qualified teachers of English who could write coherently and cohesively.

At the level of educational research, the current study makes a significant contribution summarized in two respects:

a) It serves as an example for further studies in education in terms of using the interpretiveconstructivist research framework. This approach has been totally neglected in Egypt, no previous study having used an exploratory approach to investigate the coherence and cohesion problems faced by Egyptian student teachers of English.

b) It also serves as an example of the triangulation of research methods such as questionnaires, and semi-structured in-depth interviews. This mix of research methods has not been extensively used in Egypt before to study Egyptian participants.

In terms of curriculum planning and design, the study is potentially significant as it highlights the following:

a) It helps curriculum designers take into consideration students' needs and interests in designing their curriculum.

b) It opens curriculum planners and designers' minds to different approaches to the teaching and assessment of essay writing in general and organizational skills in particular. 


\section{Conclusion}

- The teaching materials used with Egyptian students should cover a wide range of cohesion and coherence skills coping with students' different proficiency levels.

- The teaching techniques adopted by Egyptian essay writing lecturers should be varied to help meet the needs of students with different abilities.

- Teaching and learning tasks should be graded and varied to help students make the most out of them, especially in large classes of different abilities and skills.

- The feedback practices employed by the essay writing lecturers should combine both types of oral and written feedback, be promptly given to students, be critical and constructive in nature to challenge students and help them develop the different cohesion and coherence skills.

- The assessment practices used should be formative and summative. The formative assessment practices should be regular, insightful and guiding. Use of portfolio and assignment could be good practices. The summative assessment practices should work according to a list of criteria and marked by two markers.

- Essay writing teachers should be trained to use different classroom interaction techniques and teaching methods such as pair work and group work, peer-review, student-teacher conferences and any other related techniques. It is also suggested that teachers should be acquainted with using technology in the classroom to help students with different learning styles learn efficiently and rapidly.

- It is suggested that essay writing lecturers should be engaged in conducting research in general and action research in particular where they can find students' weakness areas and try to improve them.

\section{Future Work}

The following suggested studies are areas that need more exploration with the Egyptian context:

1- Conducting a study about the effect of different teaching techniques on the development of students' organizational skills in writing.

2- Exploring teachers' views about teaching the mechanics of writing in an essay writing course.

3- Investigating the role played by different revision and editing strategies on the development of students' organizational skills.

4- Analysing students' vocabulary learning strategies and its effect on the development of coherent and cohesive written essays.
5- Investigating the effect of the current classroom interaction techniques on students' attitudes towards essay writing.

6- Analyzing the written essays of Egyptian student teachers to investigate the different writing errors in their English writing.

7- Exploring the relationship between Egyptian student teachers' performance in essay writing and their teaching practices of writing and composition at different teaching practice schools.

8- Investigating teaching essay writing creatively in an Egyptian essay writing course at the university level.

9- Investigating teacher feedback practices to understand the factors that hinder good quality teacher feedback on their students' writing.

10- Exploring the quality of the current assessment practices in all the English language courses at the English department, Helwan Faculty of Education in Egypt.

\section{References}

[1] Abdellah, G., \& Taher, S. (2007). A Novel Prospective of Competitive Mechanisms for Enhancing Higher education in Egypt. Higher education Enhancement Project (HEEP), from http://www.heep.edu.eg.

[2] Abdollahzadeh, E. (2010). Undergraduate Iranian EFL Learners' Use of Writing. Strategies. Writing \& Pedagogy, 2 (1).

[3] Al-Akloby, S. (2001). Teaching and learning English vocabulary in Saudi Arabian public schools: an exploratory study of some possible reasons behind students' failure to learn English vocabulary. Unpublished Ph.D. Thesis, University of Essex, UK.

[4] Albertson, K. (2006). College Student Perceptions of Expectations for Academic Literacy in Their First Term. Unpublished $\mathrm{PhD}$ Thesis, Indiana University of Pennsylvania, USA.

[5] Atari, O. (1983). A contrastive analysis of Arab and American university students' strategies in accomplishing written English discourse functions. Dissertation Abstracts International, 44(11), 3307A.

[6] Atay, D., \& Kurt, G. (2006). Prospective Teachers and L2 Writing Anxiety. Asian EFL Journal, 8 (4).

[7] Bacha, N. (2002). Developing Learners' Academic Writing Skills in Higher Education: A Study for Educational Reform. Language \&Education, 16(3), 161-177.

[8] Ballantyne, R., Borthwick, J., \& Packer, J. (2000). Beyond Student Evaluation of Teaching: identifying and addressing academic staff development needs. Assessment \& Evaluation in Higher Education, 25 (3), 221-236. 
[9] Barmby, P. (2006). Improving teacher recruitment and retention: the importance of workload and pupil behaviour. Educational Research 48 (3).

[10] Bell, T. (1998). Extensive reading: Why? And how? [On-line]. Internet TESL Journal, 4(12).

[11] Chakraverty, A., \& Gautum, K. (2000). Dynamics of writing. Forum, 38(3).

[12] Chan, A. (2010). Toward a Taxonomy of Written Errors: Investigation Into the Written Errors of Hong Kong Cantonese ESL Learners. TESOL Quarterly. $44(2)$.

[13] Cheng, Y. (2002). Factors Associated with Foreign Language Writing Anxiety. Foreign Language Annals, 35(5).

[14] Cochran-Smith, M. (2005). Teacher educators as researchers: multiple perspectives. Teaching and Teacher Education, 21(2).

[15] Cumming, A. (Ed.). (2006). Goals for academic writing: ESL students and their instructors. Amsterdam: John Benjamins.

[16] Darling-Hammond, L., \& McLaughlin, M. (1995). Policies that support professional development in an era of reform. Phi Delta Kappan, 76(8), 597- 604.

[17] Dhillon, N., Fahmy, A., \& Salehi-Isfahani, D. (2008). Egypt's Education System: Parents and Students Emerge as a New Force for Reform. Middle East Youth Intiative, Point of view, from http://www.shababinclusion.org/content/blog/detail/ $1160 /$.

[18] Doushaq, M. (1986). An Investigation into Stylistic Errors of Arab Students Learning English for Academic Purposes. ERIC, EJ347409.

[19] Edelsky, C. (1982). Writing in a bilingual program: the relationship of $\mathrm{L} 1$ and $\mathrm{L} 2$ Texts. TESOL Quarterly, 16(2), 211-228.

[20] Eid, G., Sultan, D., Sayed, R., \& Zekri, M. (2007). Freedom of Opinion \& Expression in Egypt. Egypt. http://www.openarab.net/en/node/274.

[21] El-Hibir, B. and Al-Taha, F. (1992). Orthographic errors of Saudi students learning English, Language Learning Journal, 5 (1), 85 - 87.

[22] Elkhatb, A. (1983). Toward a Descriptive Rhetoric of the ESL Paragraph. ERIC, ED234622.

[23] El-Koumy, A. (1997). Exploring the ReadingWriting Relationship in NES and EFL Students. ERIC, ED413781.

[24] El-Mortaji, L. (2001). Writing ability and strategies in two discourse types: A cognitive study of multilingual Moroccan university students writing Arabic (LI) and English (L3). Dissertation Abstract
International, 62(4), C499.

[25] Ferris, D., \& Hedgcock, J. (1998). Teaching ESL Composition: Purpose, Process, and Practice. Mahwah, NJ: Lawrence Erlbaum Associates.

[26] Ferris, D., \& Hedgcock, J. (2004). Teaching ESL Composition: Purpose, Process, and Practice. $2^{\text {nd }}$ ed. Mahwah, NJ: Lawrence Erlbaum Associates.

[27] Gouma, M. (2008). Parliamentary Anger in Egypt for punishing a male student who criticized President Mubarak. Aljazeera Net. Retrieved 21/6/2008, from http://www.aljazeera.net/NR/exeres/2F04B2172512-4948-9E5A-A86AC2AD2E28.htm.

[28] Güneyli, A., \& Aslan, C. (2009). Evaluation of Turkish prospective teachers' attitudes towards teaching profession. Procedia Social and Behavioral Sciences 1

[29] Halliday, M., \& Hasan, R. (1985). Language, context, and text: Aspects of language in a social semiotic perspective. Deakin: Deakin University.

[30] Hassan, B. (2001). The Relationship of Writing Apprehension and Sef-Esteem to the Writing Quality and Quantity of EFL University Graduates. ERIC, ED459671.

[31] Hayes, C. (1981). Exploring Apprehension: Composing Processes of Apprehensive and Nonapprehensive Intermediate Freshman Writers. ERIC, ED210678.

[32] Heller, M. (1999). Reading-Writing Connections: From Theory to Practice. Mahwah, NJ: Lawrence Erlbaum Associates.

[33] Hinkel, E. (2004). "Rhetorical Features of Text: Cohesion and Coherence", Teaching Academic ESL Writing: Practical Techniques in Vocabulary and Grammar. Lawrence Erlbaum Associates, Mahwah, New Jersey, p.265.

[34] Holliday, A. (1996). Large-and small-class cultures in Egyptian university classrooms: A cultural Justification for curriculum change. In H. Coleman (Ed.), Society and the Language Classroom (pp. 86104). Cambridge: Cambridge university press.

[35] Hong, W., Xuezhu, C., \& Ke, Z. (2007). On the relationship between research productivity and teaching effectiveness at research universities. Frontiers of Education in China, 2(2), 298-306.

[36] Jarzabkowski, L. (2001). The social dimensions of teacher collegiality. Paper presented at the The annual conference of the Australian Association of Research in Education, Notre Dame University, Perth.

[37] Kurt, G. \& Atay, D. (2007). The effects of peer feedback on the writing anxiety of prospective Turkish teachers of EFL. Journal of Theory and Practice in Education, 3(1), 12-23. 
[38] Langer, J. (1983). Effects of Topic Knowledge on the Quality and Coherence of Informational Writing. ERIC, ED234418.

[39] Larios, J., Marin, J., \& Murphy, L. (2001). A Temporal Analysis of Formulation Processes in L1and L2 Writing, Language Learning. 51(3).

[40] Lee, C. (2004). Seeing is Understanding: Improving Coherence in Students' Writing. The Internet TESL Journal, X (7), http://iteslj.org/.

[41] Lee, S. (2006). Teaching EFL Writing in the University: Related Issues, Insights, and Implications. Journal of National Taipei Teachers College, 16 (1).

[42] Leki, I. (1991). Twenty-five years of contrastive rhetoric: Text analysis and writing pedagogies. TESOL Quarterly, 25(1).

[43] MacIntyre, P., NoelS, K., \& Clement, R. (1997). Biases in self-ratings of second language proficiency: The role of language anxiety. Language Learning, 47, 265-287.

[44] Mitchell, S., Reilly, R., \& Logue, M. (2009). Benefits of collaborative action research for the beginning teacher. Teaching and Teacher Education, 25(2).

[45] Mohamed, A., \& Omer, M. (2000). Texture and Culture: Cohesion as a Marker of Rhetorical Organisation in Arabic and English Narrative Texts. RELC Journal, 31(2), 45-75.

[46] Mourtaga, K. (2004). Investigating writing problems among Palestinian students studying English as a foreign language. Dissertation Abstracts International, 66 (1), 63.

[47] Myhill, D. (2009). Becoming a designer: Trajectories of linguistic development. In Bear, R., Myhill, D., Riley, J., Nystrand, M. The Sage Handbook of Writing Development. (pp.402-13). London: Sage Publications.

[48] Nunan, D. (1999). Second language teaching and learning. Boston: Heinle and Heinle Publishers.

[49] Qaddumi, M. (1995). Textual deviation and coherence problems in the writings of Arab students at the University of Bahrain: sources and solutions. Unpublished Ph.D. Thesis, University of Nottingham, United Kingdom.

[50] Ramsden, P., Prosser, M., Trigwell, K., \& Martin, E. (2007). University teachers' experiences of academic leadership and their approaches to teaching. Learning and Instruction, 17.

[51] Rao, Z. (2007). Training in brainstorming and developing writing skills. ELT Journal, 61 (2).

[52] Reid, J. (1993a). Historical perspectives on writing and reading in the ESL classroom. In J. Carson \& I. Leki (Eds.), Reading in the composition classroom:
Second language perspectives (pp. 33-60). Boston: Heinle.

[53] Richards, A. (1992). Higher Education in Egypt. Education and Employment Population and Human Resources Department. Working Papers. The World Bank.

[54] Rose, M. (1985). Complexity, rigor, evolving method, and the puzzle of writer's block: Thoughts on composing-process research. In M. Rose (Ed.), When a writer can't write (pp. 227-260). NY: Guilford Press.

[55] Santos, S., \& Suleiman, M. (1993). Teaching English to Arabic-Speaking Students: Cultural and Linguistic Considerations. ERIC (ED360876).

[56] Scordaras, M. (2003). English language learners' revision process in a college composition class. Dissertation Abstracts International, 64(8), 2815.

[57] Selfe, C. (1984). The Predrafting Processes of Four High- and Four Low-Apprehensive Writers. Research in the Teaching of English, 18(1), 45-64.

[58] Shawky, H. (2006). The president intervenes to pass Alaa and Al-Gamal announces her success in the Arabic language exam, Al-Masry Alyoum, http://www.almasryalyoum.com/article2.aspx?ArticleID=21966.

[59] Shokrpour, N., \& Fallahzadeh, M. (2007). A Survey of the Students and Interns' EFL Writing Problems in Shiraz University of Medical Sciences. Asian EFL Journal, 9(1).

[60] Thompson-Panos, K., \& Thomas-Ruzic, M. (1983). The least you should know about Arabic: implications for the ESL writing instructor. TESOL Quarterly 17(4), 609-623.

[61] Tyson, R. (1997). Motivation, Self-confidence, and the Process Approach in Korean University Writing Classes. Paper presented at the 1997 National Korea TESOL Conference, Kyongju.

[62] Zamel, V. (1992). Writing one's way into reading. TESOL Quarterly, 26(3), 463-485.

[63] Zheng, Y. (1999). Providing the students with effective feedback in the writing process. Teaching English in China, 36. 